\title{
Curriculum for undergraduate business management students: The views of the business sector
}

\author{
B. J. Erasmus \\ University of South Africa, Pretoria \\ e mail: erasmbj@unisa.ac.za \\ P. v. Z. Loedolff \\ University of South Africa, Pretoria \\ e mail: Loedop@unisa.ac.za
}

\begin{abstract}
The presentation of undergraduate Business Management degrees that are relevant to the needs of the business community is an ongoing challenge. The content of the degree structure therefore has to be adapted constantly to meet the ever changing needs of the business community. This study focuses on the broad educational competencies identified by selected South African businesses for the curricula for undergraduate business management degrees. The business management areas investigated were: general management, marketing manage ment, financial management, risk management, human resource management and entrepreneurship. The nominal group technique was used, with between six and 15 specialists chosen from each of these areas from the business community. $A$ total of 48 such specialists participated in the study. Although each area of business holds unique challenges, the results indicated a requirement for generic competencies which are vitally important for the degree programme, irrespective of the specialist field. The study concludes with certain recommendations.
\end{abstract}

\section{INTRODUCTION}

Over the past few years, the Minister of Education has announced drastic changes to the higher education landscape in South Africa. The mergers and rationalisation plans prescribed by the state have included, among other things, the merging of various higher education institutions (universities and technikons) and, as a result, the total number of these institutions will soon be reduced from 36 to 21 institutions of higher learning (Jansen 2003, 29). One of the most significant mergers in the higher education distance learning fields is the merger between the University of South Africa $( \pm 180000$ students) and the Technikon of Southern Africa ( \pm 60000 students). The new, merged institution will be one of the megadistance education universities in the world, with a total student body of \pm 250000 (www.unisa.ac.za/merger), the business management student body accounting for \pm 50000 of this number. The new University of South Africa consequently has an enormous responsibility when it comes to teaching relevant business management 
principles and contributing to the education of managers and leaders in South Africa. Its role and importance in influencing the business community is farreaching and must not be underestimated.

It is a fundamental requirement that in order for any degree in business management to be relevant to the workplace, the outcomes and content of such a degree should be aligned with the requirements of the business world. Linked to this is the consideration that the management environment has undergone significant changes during the recent past - both locally and internationally - and that uncertainty existed within the institutions as to whether the wide variety of degrees offered in business management and their current and planned curricula were still relevant in this new context.

\section{THE SCOPE OF STUDIES IN BUSINESS MANAGEMENT AND THE KEY STAKEHOLDERS}

Business management involves the study of the ways in which business organisations can be managed effectively and efficiently. It examines how the limited resources (human resources, physical resources such as raw materials, financial resources, information resources and knowledge) available to the entrepreneur or businessperson can be utilised in the most productive way to profitably supply products and services to the marketplace. According to Cronje, Du Toit and Motlatla (2004, 24), Business management is concerned with the study of those institutions in a particular economic system that satisfies the needs of a community. In a mixed market economy, as is found in South Africa, private business organisations are the main area of study. Linked to this is the task of business management, which is to determine how an organisation can achieve the highest possible output (products and services) with the least possible input. 'More specifically, it entails an examination of the factors, methods, and principles that enable a business to function as efficiently and productively as possible in order to maximise profit' (Cronje et al. 2004, 25).

According to Macfarlane and Ottewill $(2001,9)$, the purpose of a business management curriculum is often conceived in terms of providing students with the skills and knowledge required to participate in some form of business activity. They argue that, from this perspective, 'business and management education is a study "for" business with the essential purpose of equipping learners for the needs of commerce, industry and public service' $(2001,9)$. However, they also suggest that, in wider terms, the purpose of business and management education is a study about the nature of business activity. 'This implies an analysis of the role of business in society deploying sociological, economic, philosophical and other perspectives which enable learners to develop a critical understanding of business as a social phenomenon' (Macfarlane and Ottewill 2001, 9). With reference to the work of Brown and Harrison (1980), Boys (1988), and Grey and French (1996), Macfarlane and Ottewill $(2001,10)$ suggest that most analysts of the aim of 
business and management education argue that studying for business tends to dominate the curriculum. However, in reality, most courses of study embody aims from across the spectrum. This includes both applied knowledge and skills and critical evaluation of business as a social activity.

Liyanage and Poon $(2003,1)$ argue that management studies are not only about theoretical constructs, but also about practical resolutions and problem solving in the real business world. This view is supported by Elliott and Glaser (1998, 2), who suggest that management education should emphasise both theory and practice, but that the real focus should be on catering for the needs of industry and business. By implication, higher education distance learning institutions should ensure that programmes and courses in business management cater for both these needs. A second consideration is that education in business management and its future development cannot be separated from either the context of national education policy or the various stakeholders.

Macfarlane and Ottewill $(2001,11-12)$ contend that 'within the parameters of national education policy, a particular issue for business and management educators is the extent to which they should tailor the curriculum to meet the current, perceived needs of employers and the wider business community or rely on their own judgement as to the requirements of learners'. The same authors argue that employers and the wider business community should be the key stakeholders as far as the business management curriculum is concerned $(2001,12)$. Elliott and Glaser $(1998,1)$ agree, suggesting that higher education in business and management should move closer to industry, to bring industry into their confidence and to enable curricula to reflect the needs of industry.

Standards within the South African education system are governed by the South African Qualifications Authority (SAQA) and the National Qualifications Framework (NQF) (van Dyk, Nel, Loedolff and Haasbroek 2001, 44). In essence, SAQA and the NQF require any qualification offered by a higher education learning institution to reflect a defined purpose and to be based on learning outcomes that are intended to qualify learners with applied competencies and a basis for further learning. It means the formal recognition of the achievement of the required number of credits at specific levels of the NQF, as determined by the relevant bodies registered for such purposes (SAQA 2000, 3). The requirements of the National Qualifications Framework in South Africa and the focus on learning outcomes have already compelled higher education institutions to align their curricula, programmes and courses with the requirements of outcomes-based education (Erasmus and van Dyk 2003, 14). Whereas the focus was traditionally on what may be described as content, the focus is now on the desired outcomes.

From the above it can be concluded that the various programmes in business management in South Africa should be aligned with both the needs of the business community and the requirements of the national education system. Furthermore, programmes in business management should not only involve study 'about' business, but also study 'for' business. This means that higher education in 
business management should cater for the needs of industry and business, as key stakeholders. Finally, it is crucial that higher education distance learning institutions which provide management education should not only stay abreast of developments in the field of business management, but should also align their programmes and courses to the requirements of SAQA, on the one hand, and the needs of business and best practice on the other.

\section{OBJECTIVE OF THE STUDY}

The objective of this study was to determine what selected members of various business organisations expected of undergraduate students in business management when they enter the business environment.

\section{RESEARCH DESIGN}

\section{Sampling}

The total population for this type of study would be the total number of businesses in South Africa. For the purpose of this study, it was decided to draw a sample of 12 to 15 business managers from the most important representative sectors of business management (e.g. general management, marketing management, risk management, human resource management and financial management).

The sampling method used was a non-probability sampling technique known as a purposeful sample. Such sampling is done with a specific purpose in mind and it is therefore necessary to select participants from predefined groups. This method of sampling can also be described as expert sampling, as it involves assembling a sample of persons with known expertise in specific areas. In the current study it was more important to select participants from specialised areas who could provide relevant ideas and insights, than sampling for proportionality. This type of sampling method is very useful for exploratory research (which is what this study is).

Company executives or their personal assistants were contacted by telephone and informed about the aim of the study. They were asked whether they would be prepared to participate in the study and represent their company and the specific sector in which they are involved. After this initial telephone contact, the relevant executives were also contacted via e-mail and facsimile and asked to confirm their participation in the study and to indicate which session they or other members of their staff would attend.

Details of the sectors included in the various groups are given in Table 1.

Table 2 indicates the various areas of business/nominal groups, together with the representation, per sector, of the various participants. 


\section{Research instrument}

Because of the nature of the information required, the researchers decided to follow a qualitative approach. This would enable the researchers to gain an indepth knowledge of the views and opinions of corporate executives from the selected organisations. The technique known as the Nominal Group Technique (NGT) was chosen, since this would provide an environment that would enable company representatives to submit their individual ideas in a structured fashion and provide academic personnel with an indication of the relative importance of these inputs in terms of both current and future curricula.

The Nominal Group Technique (NGT) is a very useful technique in qualitative research for obtaining maximum input from group members while limiting unnecessary personal conflict within groups. This technique was originally developed by Delbecq and van de Ven and is in essence a structured brainstorming technique. It has one of its features the way it regulates group inputs and decision selections, while opportunities for conflict are limited by the way the decision process is structured. Each member of the group has an equal chance to contribute without any fear of domination by other members of the group. The NGT process comprises the following four phases as described by Gepson, Martinko and Belina (Training and Development Journal September 1981):

- Step 1: Idea generation. Members of the group are given the opportunity to study the problem quietly and generate ideas which they write down or key in.

- Step 2: Round-robin feedback from members. Each member of the group in turn is now given the opportunity to share one idea with the rest of the group. The idea is written down or reflected on the projection screen. The reporting of ideas is then continued with a second and third round and so on until all ideas are written down.

- Step 3: Discussion to clarify. Each recorded idea is then examined and discussed in order to clarify uncertainties.

- Step 4: Prioritising of ideas. Members of the group now individually select the best ideas (normally a maximum of ten) and rate the importance of each idea on a 10-point scale. The totals of all members in the group are then determined and the priority sequence is determined mathematically.

The researchers also decided on the NGT because the participants came from various institutions and organisations and held diverse positions and, were likely to have diverse opinions. The NGT is also particularly useful when there are power differences between participants and when one wants to explore the degree of consensus between participants on a given topic. The NGT uses a structured approach to collecting data: the interaction between the participants is under the strict control of the facilitator (de Ruyter 1996, 44). In the NGT discussion is kept to a minimum and is only used for clarification purposes. 
Table 1: Sectors, sample and number of participants in the various groups

\begin{tabular}{|c|l|c|c|}
\hline Serial & \multicolumn{1}{|c|}{ Sector } & $\begin{array}{c}\text { Sample } \\
\text { drawn }\end{array}$ & Participants \\
\hline 1 & Agriculture, hunting, forestry and fishing & 2 & 0 \\
2 & Mining & 8 & 1 \\
4 & Manufacturing & 39 & 3 \\
5 & Electricity, gas and steam & 4 & 9 \\
6 & Construction & 5 & 3 \\
7 & Transposale and retail storage and communication & 16 & 2 \\
8 & Financing, insurance, real estate and business & 34 & 6 \\
9 & services & 7 & 20 \\
0 & Computer related activities and research & 33 & 2 \\
& Community, social and personal services (including & & 2 \\
\hline
\end{tabular}

Table 2: Representation of sectors in nominal groups

\begin{tabular}{|c|c|c|}
\hline Area of business & $\begin{array}{c}\text { Participants per } \\
\text { group }\end{array}$ & $\begin{array}{l}\text { Sectors and number of } \\
\text { participants per sector }\end{array}$ \\
\hline General management & 12 & $\begin{array}{l}\text { Mining (1) } \\
\text { Electricity, gas and steam (2) } \\
\text { Manufacturing (1) } \\
\text { Government departments (1) } \\
\text { Financing, insurance, real estate and business } \\
\text { services (2) } \\
\text { Computer related services and research (2) } \\
\text { Transport and communication (3) }\end{array}$ \\
\hline Marketing management & 8 & $\begin{array}{l}\text { Manufacturing (2) } \\
\text { Construction (1) } \\
\text { Financing, insurance, real estate and business } \\
\text { services (4) } \\
\text { Transport and communication (1) }\end{array}$ \\
\hline Financial management & 8 & $\begin{array}{l}\text { Electricity, gas and steam (2) } \\
\text { Construction (1) } \\
\text { Wholesale and retail (1) } \\
\text { Financing, insurance, real estate and business } \\
\text { services (3) } \\
\text { Transport and communication (1) }\end{array}$ \\
\hline Risk management & 8 & $\begin{array}{l}\text { Electricity, gas and steam (3) } \\
\text { Financing, insurance, real estate and business } \\
\text { services (5) }\end{array}$ \\
\hline
\end{tabular}




\begin{tabular}{|l|c|l|}
\hline \multicolumn{1}{|c|}{ Area of business } & $\begin{array}{c}\text { Participants per } \\
\text { group }\end{array}$ & \multicolumn{1}{|c|}{$\begin{array}{c}\text { Sectors and number of } \\
\text { participants per sector }\end{array}$} \\
\hline $\begin{array}{l}\text { Human resource } \\
\text { management }\end{array}$ & 6 & $\begin{array}{l}\text { Construction (1) } \\
\text { Financing, insurance, real estate and business } \\
\text { services (3) } \\
\text { Government departments (1) } \\
\text { Transport and communication (1) } \\
\text { Electricity, gas and steam (2) } \\
\text { Financing, insurance, real estate and business } \\
\text { services (3) } \\
\text { Wholesale/retail (1) }\end{array}$ \\
\hline Total & 6 & \\
\hline
\end{tabular}

\section{Data-collection procedure}

In order to create a non-threatening environment in which participants would feel they could freely express their views and opinions, a Group Decision-making System (GDS) was used for all the nominal group sessions. This meant that each participant was provided with a computer terminal that was linked to a centralised server via a network. The participants keyed their responses into the computer, and these responses were then anonymously displayed on an overhead screen. Because responses could be given anonymously, an environment was created in which participants could freely air their views, without being criticised by other participants or members of the research team.

Each of the nominal group sessions was conducted in exactly the same manner and a short explanation of the daily research process is given in the following discussion.

The facilitator welcomed the participants and thanked them for their attendance and the contribution they were about to make. They where then introduced to the research team and the academic personnel, whereupon they introduced themselves to the rest of the group, stating their position and the company they represent. This form of introduction helped the participants to feel at ease. An academic staff member provided the participants with a short description of the aim of the research and the results/outputs required from the session. Once consensus about the aim of the upcoming session was reached, the facilitator took charge of the rest of the proceedings.

A typical session/meeting started when each participant was registered on the system. Once this was done, the participants took up their positions behind their workstations. A facilitator facilitated the session/meeting to ensure that the outcomes of the session were attained. When, for instance, a brainstorming session was held, each participant was invited by the facilitator to take part in the particular exercise. All the participants were then provided with the opportunity to key in their suggestions on their respective workstations. All the suggestions, which were 
anonymous, were then submitted to the leader's station. The suggestions were then displayed with a data projector on a screen. Through a voting system, the participants could then rank or rate the suggestions. The result of the ranking or rating indicated the mean standard deviation and other statistics. At the end of the session, a report was generated by the software package with which all the results were captured.

After clustering the items together, the various competencies (outputs) were prioritised by using a voting tool. Before rating and ranking the issues, the facilitator made sure that all the participants understood clearly what was meant under each of the items. In some cases terms had to be either rephrased or divided into two separate concepts in order to avoid misinterpretation of the items. After each voting session the facilitator asked the participants and academics whether the results yielded any surprises. This question led to a discussion on the results of the voting.

\section{Limitations of the study}

Although the GDS can and does capture participants' responses on computer, it cannot capture the qualitative remarks and discussions between participants. To overcome this shortcoming and prevent the loss of valuable inputs, the researchers made notes of everything the participants said that could not be captured by the GDS system.

One of the disadvantages of nominal groups is that the findings cannot always be generalised and one cannot assume that they apply to the whole population. This is due to the limited number of participants and the likelihood that the participants will not be a representative sample of the whole sector. Bearing this drawback in mind, the nominal groups where scheduled in such a way that they included individuals from different sectors, different companies, and different functional areas within those companies. This provided the researchers and academic personnel with a rich spread of views and opinions, which is sufficient for this type of explorative research. The aim of the research was not to be able to generalise the results to apply to the whole population, but to obtain specific inputs on a selected type of organisation and sector. This means that the results are representative of the specific sample at hand.

\section{Positive aspects of the study}

The interaction between the participants enabled them to direct questions at each other, at the researchers, and at the academic staff, for example: For which management level do you require our inputs? Some of the questions raised by academic staff were as follows: What are the new issues that would be important for managers in five years from now? What must be the profile of someone who enters the organisation as a graduate in business management? This allowed them 
to re-evaluate and reassess their own beliefs and understanding of specific issues and led to some very interesting debates. The debates highlighted certain concepts and showed the relative unimportance of other issues. They also made it possible for the participants to share and explain their views, beliefs and feelings about the topic under discussion.

Because each participant came from a different sector and position, each of them responded from within a specific context. By inviting the participants to ask questions and by encouraging discussion, the researchers, academic personnel and also the participants were able to get to the bottom of what was said. The participants and researchers therefore got a clear understanding of what everyone meant.

\section{Data analysis}

The researchers and academic staff received three lists of results obtained from each nominal group session. List 1 contained the edited list of all the focus areas (outputs, outcomes, skills and competencies) identified by the participants. List 2 contained 10 responses, each with a rating of between 1 and 10. List 3 contained an identical list of items, but these items were ranked in order of importance.

These separate lists were each used differently during data analysis. While list 2 provided the researchers and academic personnel with an indication of the importance of each issue to be included in the curricula, list 3 gave them an indication of which items should carry the most weight when tested during an assessment. The academic staffs were given the results of their specialist area and were responsible for the exploration and evaluation of the research results.

\section{RESEARCH RESULTS}

\section{Introduction}

Owing to the information obtained from the nominal group process, the researchers and responsible degree heads were in a position to: (1) compare the requirements identified for the various degrees with the current curricula and courses; (2) use the results of the ranking to determine the relative importance of the various focus areas identified; and (3) identify similarities and gaps in current curricula. However, this is not reflected in this study.

The requirements of the various business areas

\section{Introduction}

Appendix 1 reflects the results of ranking the various competencies required for each business area. Given the fact that the ranking process indicated the relative importance of each competency (output) within a particular business area, no specific general pattern emerged in the results. The results of the ranking provided 
an indication of the relative importance of the various competencies in curriculum design and assessment. The implications of the findings in respect of the top five competencies required for each business area will be discussed briefly.

\section{General management}

According to the findings, the most important requirement in general management is people management skills (those very specific task-related competencies that are needed to attain organisational goals in an effective and efficient manner through people). It includes the ability to communicate with employees, to establish strong interpersonal relations and to build co-operative, satisfying relationships among workgroup members. This means that the learner must be trained in all aspects of managing and motivating people, and must be trained in interpersonal communication and interpersonal relations.

The requirement of strong financial acumen implies financial skills and the ability to understand and manage cost structures and drivers of cost. It also requires the ability to understand and interpret financial data and information in order to manage cost, and to analyse and forecast business needs and cost implications.

The ability to strategise requires the ability to understand and apply the strategic planning process, to develop business plans and to integrate functional strategies.

The nominal groups emphasised the need for a general manager to be multiskilled in terms of the various aspects of managing a business and the processes in the enterprise.

The graduate must therefore be prepared to deal with all functions of business.

The requirement of the ability to prepare a marketing plan and a human resources plan is, in fact, closely linked to the requirement to strategise and prepare business plans.

The nominal group exercise highlighted a number of gaps in the current curricula in general management. The biggest gap at present is the lack of emphasis on managing cost structures and drivers of cost and the lack of emphasis on the interpretation of financial data and information.

\section{Risk management}

The nominal group felt that, at the lower level, the focus should be on the interpretation of risk. This is why this particular competency was identified as the most important one. The abilities to conduct risk assessments, produce a risk management plan, co-ordinate the risk-management process and produce a riskevaluation model are all considered equally important. The nominal group pointed out that not everyone will be working with all the outputs at the same time, but the graduate should be in a position to work in any of these competency areas.

The competencies identified by the nominal group are all covered in current curricula and in the modules that make up the degree in risk management. The 
only two exceptions are: (1) corporate governance and compliance; and (2) the coordination of the risk management process. These were identified by the nominal groups as competencies that should be catered for in undergraduate studies.

\section{Human resource management}

The results produced by the nominal group revealed a couple of competencies that are not adequately catered for at present. Although all the functional aspects of human resource management are covered in the existing curricula, the following require more attention:

- The ability to compile, present and interpret basic statistical information. At present, students are not exposed specifically to this sort of information, unless they take Statistics as one of the optional modules. This study clearly indicated that statistics should be compulsory for all HRM students.

- Facilitation and presentation skills. Current curricula do not adequately cater for the practical application of these skills, although the psychological and theoretical aspects of facilitation are covered.

- The ability to formulate basic HRM policy. Students are provided with examples of policy documents in HRM, but are currently not required to formulate or compile HRM policy.

\section{Marketing management}

Of the top five competencies identified, perhaps two should be given further consideration.

Given the emphasis placed on graduates' ability to prepare a marketing plan, greater attention has to be given to this in undergraduate studies in order to cover all aspects of marketing planning.

The research indicated clearly that students require a solid understanding of the financial implications of all marketing decisions, in other words, the bottom line. Although this issue is addressed in places in the current study material, it is felt that more emphasis must be placed on this competency.

\section{Financial management}

Virtually all the competencies the nominal group identified for financial management are currently catered for in the curricula. The only area which requires more attention is the preparation of a business plan, since this is an important aspect in all enterprises. Financial managers play a vital role here.

\section{Entrepreneurship}

The competency requirements for entrepreneurship are, for understandable reasons, closely linked to those of the general manager and, consequently, general 
management and multifunctional skills are essential. The entrepreneur must also have specific competencies in financial management and business planning. The entrepreneur should therefore be able to operate across all functional areas and have the ability to integrate the various functions of business.

The competencies of implementing a business plan and networking are, at present, gaps in the curricula of the entrepreneurship programme.

\section{Generic requirements for all undergraduate programmes}

The generic competencies that were identified across all the areas of business are of special importance and are equally crucial for the purposes of curriculum design (i.e. for the degree as a whole).

These generic competencies are as follows:

- Financial management. This includes budgeting, cash flow management, etc, all of which should become an integral part of the degrees offered in business management.

- Business planning. The elements of business planning and practical exposure to the preparation of a business plan (or parts of a business plan) must be incorporated in all the degrees offered in business management.

- Integration. Before graduating, learners should get exposure to the function of integrating the various functions of business.

- Strategic management. Exposure to the various aspects of strategic management is also essential, regardless of the degree specialisation. The entrepreneur, the financial manager, the human resource specialist, the marketing manager and the general manager should all be able to apply the various concepts, principles and processes of strategic management in their daily work.

- General management skills. All graduates in business management must have general management skills, including soft skills such as interpersonal and communication skills.

- Multifunctional skills. Graduates in general management and entrepreneurship require multifunctional skills, that is, the ability to function across all areas of business.

\section{Overall implications of the study and challenges for the future}

If higher education distance learning institutions want to be competitive in terms of producing graduates in business management who compare favourably with those who receive their education at residential universities, it is essential that such distance learning institutions teach their learners not only about business, but also prepare them for business. This, in turn, requires a clear understanding among academics of the needs of industry and business. It further requires clarity on the 
type of outputs required of graduates when they enter employment in industry and commerce and, finally, it requires the alignment of curricula and programmes with these outputs.

The results of this study have confirmed that there is a need, in South Africa, for specialisation within the BCom degree programme and that the existing fields of specialisation should be retained. However, given the variation in businesses (i.e. from small to large, to multinational), students at the undergraduate level should be trained in certain generic competencies that are required in all businesses, regardless of their size.

The generic requirements identified by the nominal groups should be compulsory for all the specialisation degrees. A special effort will have to be made to ensure that all graduates are equipped with competencies such as business planning, strategic planning, general management and financial management skills, as well as the ability to integrate the various business functions.

The emphasis placed by the business community on output, on outcomes and on applied competencies, reinforces the need for higher education in business management to be outcomes-based and to be aligned with the requirements of the national education policy. Content-based education is simply no longer an option in higher education.

\section{CONCLUSIONS AND RECOMMENDATIONS}

Involving the business sector in providing inputs on the practical relevance of some of the specialisation degrees proved to be an extremely worthwhile exercise. Both the participants and the academic staff involved found this initiative informative and meaningful. The participants from industry and commerce were very impressed by the fact that the institution took the initiative to consult with them on these issues.

The process of consultation with the business community highlighted a number of issues that are considered important by employers in both industry and commerce. Although many of the issues that were identified are already addressed in the various degrees, one must acknowledge that the process revealed a number of shortcomings, all of which have to be addressed in the next cycle of curriculum planning and revision of the new degrees to be offered with effect from 2007/2008. Examples of such shortcomings were the lack of emphasis on managing cost structures and drivers of cost and the lack of emphasis on the interpretation of financial data and information in the General Management programme. In the case of the degree in Marketing Management insufficient attention is given to marketing planning.

The following recommendations are put forward for future consideration:

- Although the research had, as its primary aim, obtained information from the business sector and included employees from relatively large companies, it is 
important to repeat the study with participants from small and medium enterprises (SMMEs).

- The results of this study cannot be considered in isolation when academics embark on a curriculum review process. Although the findings and results of this study must play an important role in the curriculum redesign process, it is essential that inputs from other sources, such as benchmarking with local and overseas tertiary institutions, also be considered.

\section{BIBLIOGRAPHY}

Crabtree, B. J., M. K. Yanoshik, W. L. Miller and P. J. O’Connor. 1993. Selecting individual or group interviews. In Successful focus groups: Advancing the state of the art, ed. D. L. Morgan. Newbury Park, Calif: Page Publishers.

Cronje, G. J., G. S. du Toit and M. D. C. Motlatla. 2004. Introduction to business management. Cape Town: Oxford University Press.

Delbecq, A.1., A. H. van de Ven and D. H. Gustavson. 1970. Nominal group techniques for involving clients and resources in program planning. Academy of management proceed ings:208 227.

de Ruyter, K. 1996. Focus versus nominal group interviews: A comparative analysis. Marketing Intelligence and Planning 14 (6):44 50.

Elliott, G. and S. Glaser. 1998. Australian management education at the cusp. Journal of Management Development 17 (2):121 130.

Erasmus, B.J. and P. S. van Dyk. 2003. Training management in South Africa. Cape Town: Oxford University Press.

Gordon, W. and R. Langmaid. 1988. Qualitative market research. Aldershot: Gower.

Gepson, J., M. J. Martinko and J. Belina. 1981. Nominal group techniques. Training and Development Journal 35 (9).

Jansen, J. D. 2003. On the state of South African universities. South African Journal of Higher Education 17 (3):9 12.

Liyanage, S. and P. S. Poon. 2003. Technology and innovation management learning in the knowledge economy. The Journal of Management Development 22 (7):579 602.

Macfarlane, B. and R. Ottewill. 2001. Effective learning and teaching in business management. London: Kogan Page.

Magill, S. L. and R. P. Herden. 1998. Using educational outcomes and student profiles to steer management education. Journal of Management Education 22(5).

Nkomo, M. 2000. The National Qualifications Framework and curriculum development. Pretoria: South African Qualifications Authority.

van Dyk, P. S., P. S. Nel, P. V. Z. Loedolff and G. D. Haasbroek. 2001. Training management: A multi disciplinary approach to human resource development in Southern Africa. Cape Town: Oxford University Press.

Webster, E. 2004. Technology developments create new study methods. Business Day 13 April:15. 